\title{
Matrix metalloproteinases and bronchiolitis obliterans: Wrapping the enigma in a riddle
}

\author{
Chadrick E. Denlinger, MD
}

See related article on pages 1194-202.

Bronchiolitis obliterans (BO) is a condition of progressive collagen deposition in the airways leading to the occlusion of small bronchi and diminished pulmonary function. This condition remains the primary disease limiting long-term survival of patients undergoing lung transplants. The risks for progression of $\mathrm{BO}$ include the initial ischemiareperfusion injury, with an increased risk of $\mathrm{BO}$ associated with primary graft dysfunction in the early posttransplant phase. Additional risks for BO include episodes of increased local inflammation, such as acute graft rejection, gastroesophageal reflux disease, and infection with cytomegalovirus, bacterial, and fungal species. ${ }^{1}$ Each of these conditions increases the inflammatory process within the transplanted lungs and has been associated with the profibrotic state associated with $\mathrm{BO}$. The development of BO has been associated with release of various matrix metalloproteinases (MMPs), and MMP-9 in particular has been identified as a marker for $\mathrm{BO}$.

A recent meta-analysis has demonstrated the efficacy of azithromycin for slowing the progression and partially reversing the effects of bronchiolitis obliterans. ${ }^{2}$ A prospective, randomized trial has also demonstrated the efficacy of azithromycin as a prophylactic agent that reduces the incidence of $\mathrm{BO}^{3}$ Its use has become increasingly prevalent, although its mechanisms of action in this disease process are not completely understood. One proposed mechanism of action is that azithromycin reduces an airway biofilm of Pseudomonas colonization that is present in $30 \%$ to $40 \%$ of lung transplant recipients. The airway colonization is associated with chronic inflammation and neutrophilia contributing to BO. In addition to antibacterial activity, azithromycin is known to have activity against some viral infections, which could have similar indirect anti-inflammatory effects. ${ }^{1}$ Azithromycin has also been shown to have numerous

\footnotetext{
From the Division of Cardiothoracic Surgery, Medical University of South Carolina, Charleston, SC.

Disclosures: Author has nothing to disclose with regard to commercial support.

Received for publication Dec 21, 2014; accepted for publication Dec 22, 2014; available ahead of print Jan 22, 2015.

Address for reprints: Chadrick E. Denlinger, MD, 25 Courtenay Dr, ART Suite 7018, Charleston, SC 29425 (E-mail: denlinge@musc.edu).

J Thorac Cardiovasc Surg 2015;149:1203-1004

$0022-5223 / \$ 36.00$

Copyright (c) 2015 by The American Association for Thoracic Surgery

http://dx.doi.org/10.1016/j.jtcvs.2014.12.051
}

direct modulatory effects on inflammation and fibrosis that are unrelated to antibacterial activity. ${ }^{1}$ For example, azithromycin has been shown to suppress the interleukin (IL)17-induced release of IL-8 and 8-isoprostane from smooth muscle cells and to attenuate the autophagic effect of airway smooth muscle cells. Numerous studies have also demonstrated that azithromycin modulates the immunologic response to lipopolysaccharide and has a net effect of favoring the $\mathrm{T}_{\mathrm{H}} 2$ response rather than the proinflammatory $\mathrm{T}_{\mathrm{H}} 1$ response.

Patients found to have the best response to treatment with azithromycin are those with prominent airway neutrophilia and an abundance of MMP-9. In this issue of the Journal, Krenn and colleagues ${ }^{4}$ report their evaluation of the effect of adding the broad-spectrum MMP inhibitor tanomastat to azithromycin on the development of bronchiolitis obliterans in a rat lung allograft transplant model. Combined treatment with azithromycin and tanomastat demonstrated the greatest histologic benefit in reducing $\mathrm{BO}$, as indicated by the absence of any animals with complete airway occlusion among those treated with both azithromycin and tanomastat; however, similar numbers of animals in each treatment group demonstrated high-grade chronic rejection. Interestingly, tanomastat reversed the positive cytokine trends induced by azithromycin, suggesting that it may counteract the positive effects of azithromycin. For example, the proinflammatory cytokines interferon gamma and IL-17 were each elevated in the allograft relative to isografted lungs. Azithromycin treatment suppressed expression of both interferon gamma and IL-17, whereas the addition of tanomastat was associated with increased interferon gamma and IL-17 levels that approached those of the untreated allografts. Similarly, MMP-9 and pro-MMP-9 protein levels were suppressed by azithromycin, and the addition of tanomastat increased the levels of each to at least the levels of untreated control lungs.

The interactions of the MMPs and their endogenous tissue inhibitors are complex and not completely understood. Because tissue inhibitors of MMPs inhibit the enzymatic activity of the MMPs, there is disconnect between MMP protein levels and their activities, which may make a direct protein level assessment inaccurate as a means of determining activity. Enzymatic targets of the MMPs include other proteinases, proteinase inhibitors, clotting factors, chemotactic factors, latent growth factors, cell surface receptors, intercellular adhesion molecules, and virtually all structural extracellular matrix proteins. ${ }^{5}$ The MMPs, which comprise 2 classes, membrane bound and 
non-membrane bound, are intimately involved with regulation of the extracellular matrix by contributing to both the proteolytic and profibrotic processes. ${ }^{6}$ Specifically, the MMPs have been implicated in extracellular matrix remodeling in ischemia-reperfusion models of the heart, contributing to a profibrotic state within the myocardium. The MMPs have also been implicated in extracellular matrix degradation and the development of aortic aneurysms. $^{7}$ As a generalization, increased MMP activity correlates with degradation of the extracellular matrix. It is therefore unclear why MMP inhibition would diminish the profibrotic state of $\mathrm{BO}$.

Recognition of the importance of MMPs in the inflammatory and fibrotic process of $\mathrm{BO}$ is critical for establishing more effective treatment strategies for this common lifelimiting condition among lung transplant recipients. Krenn and colleagues ${ }^{4}$ are correct in their conclusion that MMP inhibition should be further studied to determine whether there is a therapeutic role for this type of agent in the treatment or prevention of $\mathrm{BO}$.

\section{References}

1. Vos R, Vanaudenaerde BM, Verleden SE, Ruttens D, Vaneylen A, Van Raemdonck DE, et al. Anti-inflammatory and immunomodulatory properties of azithromycin involved in treatment and prevention of chronic lung allograft rejection. Transplantation. 2012;94:101-9.

2. Kingah PL, Muma G, Soubani A. Azithromycin improves lung function in patients with post-lung transplant bronchiolitis obliterans syndrome: a meta-analysis. Clin Transplant. 2014;28:906-10.

3. Vos R, Vanaudenaerde BM, Verleden SE, De Vleeschauwer SI, WillemsWidyastuti A, Van Raemdonck DE, et al. A randomized controlled trial of azithromycin to prevent chronic rejection after lung transplantation. Eur Respir J. 2011; 37:164-72.

4. Krenn K, Gmeiner M, Paulus P, Sela N, Torres L, Zins K, et al. Effects of azithromycin and tanomastat on experimental bronchiolitis obliterans. J Thorac Cardiovasc Surg. 2015;149:1194-202.

5. Barbour JR, Spinale FS, Ikonomidis JS. Proteinase systems and thoracic aortic aneurysm progression. J Surg Res. 2007;139:292-307.

6. Eckhouse SR, Akerman AW, Logdon CB, O'Quinn EC, Nadeau EK, Stroud RE, et al. Differential membrane type 1 matrix metalloproteinase substrate processing with ischemia-reperfusion: relationship to interstitial microRNA dynamics and myocardial function. J Thorac Cardiovasc Surg. 2013;145:267-75, 277.e1-4; discussion 275-7.

7. Barbour JR, Stroud RE, Lowry AS, Clark LL, Leone AM, Jones JA, et al. Temporal disparity in the induction of matrix metalloproteinases and tissue inhibitors of metalloproteinases after thoracic aneurysm formation. J Thorac Cardiovasc Surg. 2006;132:788-95. 